\title{
Laboreal
}

Volume $8 \mathrm{~N}^{\circ} 2$ | 2012

A antropotecnologia, ferramenta ou engodo?

\section{Trabalho em centrais de atendimento a clientes : velhos modelos em novo contexto?}

El trabajo en centrales de atención al cliente : los viejos modelos en el nuevo contexto?

Le travail dans les centres d'appel : anciens modèles dans un nouveau contexte?

Work in call centres: old models in a new context?

Laerte Sznelwar e Júlia Abrahão

\section{OpenEdition}

Journals

\section{Edição electrónica}

URL: http://journals.openedition.org/laboreal/6768

DOI: $10.4000 /$ laboreal. 6768

ISSN: 1646-5237

\section{Editora}

Universidade do Porto

Refêrencia eletrónica

Laerte Sznelwar e Júlia Abrahão, «Trabalho em centrais de atendimento a clientes : velhos modelos em novo contexto? », Laboreal [Online], Volume 8 №2 | 2012, posto online no dia 01 dezembro 2012, consultado o 10 outubro 2019. URL : http://journals.openedition.org/laboreal/6768 ; DOI : 10.4000/ laboreal.6768

Este documento foi criado de forma automática no dia 10 outubro 2019.

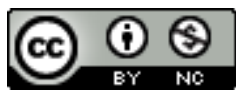

Laboreal está licenciado com uma Licença Creative Commons - Atribuição-NãoComercial 4.0 Internacional. 


\section{Trabalho em centrais de atendimento a clientes : velhos modelos em novo contexto?}

El trabajo en centrales de atención al cliente : los viejos modelos en el nuevo contexto?

Le travail dans les centres d'appel : anciens modèles dans un nouveau contexte? Work in call centres: old models in a new context?

Laerte Sznelwar e Júlia Abrahão

\section{NOTA DO EDITOR}

Manuscrito recebido em : janeiro/2012

Aceite após peritagem : setembro/2012

\section{Introdução}

1 A partir dos anos 90 a questão do trabalho em centrais de atendimento a clientes mediado por telefone e apoiado por sistemas informatizados se tornou parte integrante da cena pública, em especial para aqueles que viviam essas situações de trabalho, para os sindicalistas, para profissionais da saúde e para autoridades públicas. O fato de se tornar parte de discussões públicas não se deu apenas como uma nova oportunidade de emprego, mas sobretudo porque as conseqüências deste tipo de trabalho no âmbito da saúde dos trabalhadores logo se fizeram presentes, infelizmente de maneira negativa. Ao invés de se tornar um propulsor para o desenvolvimento profissional e para a construção da saúde dos sujeitos, conforme preconizam as abordagens da psicodinâmica do trabalho e da ergonomia, esta atividade profissional criou novos obstáculos para o desenvolvimento dos sujeitos, sobretudo porque se tornou uma fonte 
significativa de sofrimento patogênico, engendrando muitos casos de afastamento do trabalho por doenças, tais como as LER/DORT (lesões por esforço repetitivo ; distúrbios osteomusculares relacionados ao trabalho), distúrbios na esfera psíquica e até problemas da fala.

2 Nesta perspectiva, para os profissionais ligados às disciplinas que estudam e que propõem transformações no mundo do trabalho, em especial a psicodinâmica do trabalho e a ergonomia, um novo, ou melhor um enigma renovado, se constituiu. Porque um trabalho, aparentemente sem riscos maiores, se mostraria tão violento, causando problemas de saúde tão rapidamente, atingindo pessoas muito jovens, muitas vezes mulheres com menos de 25 anos. Cada vez mais evidente ficou que havia algo na maneira como aquele trabalho era organizado e o conteúdo das tarefas que os trabalhadores deveriam dar conta seriam o foco de atenção e, se possível, o centro das transformações para que esta tendência fosse invertida.

3 Um dos resultados primordiais de vários estudos desenvolvidos, mostraram que, principalmente nos casos das centrais de atendimento voltados para serviços considerados como "de massa", havia uma certa prevalência de conceitos comuns que governavam tanto o projeto de trabalho como a sua gestão. Assim, havia neste ambiente, neste tipo de negócio, algo como se fosse uma maneira muito próxima de se considerar o trabalho, isto é, algo muito parecido entre as diferentes empresas, algo simples, que fosse facilmente aprendido, que fosse passível de controle, que fosse restrito ao respeito a procedimentos bastante claros e que pudesse se repetir ao longo dos atendimentos aos clientes. Neste universo, ficou claro que havia uma maneira de definir conceitos sobre a organização e o conteúdo do trabalho que pudesse ser disseminado pelo mundo afora, uma vez que as empresas em questão, usavam metodologias parecidas, baseadas muitas vezes na importação e na tradução de conceitos, para o desenvolvimento de suas estratégias de negócio e de operação. Assim para nós, ficou em aberto um novo desafio, será que à luz da antropotecnologia, seria possível enriquecer o debate.

\section{Contribuições da antropotecnologia, da ergonomia e da psicodinâmica do trabalho}

4 A antropotecnologia, proposta por Wisner, na década de 80 do século passado, foi construída a partir de suas reflexões sobre os modelos de transferência de tecnologia e das organizações no setor industrial. Ele se inspirou nas premissas já existentes no campo da ergonomia, sendo a discrepância entre a prescrição dos engenheiros e organizadores do trabalho uma das questões transversais aos estudos e pesquisas focados na atividade dos trabalhadores. Nesta perspectiva, ele levantou uma questão um pouco mais abrangente relacionada aos desafios para que as empresas obtivessem resultados positivos no que diz respeito à saúde dos trabalhadores e a qualidade $\mathrm{e}$ produtividade em cenários muito distintos daqueles onde foram inicialmente concebidos. Portanto, a hipótese de fundo era como transferir visões do mundo da produção entre diferentes lugares da Terra, respeitando as diferenças culturais, políticas, geográficas e históricas, conseguindo resultados satisfatórios. De uma certa forma, Wisner colocou em cena a importância de se considerar uma antropologia do trabalho, uma vez que para ele não haveria diferenças entre as capacidades cognitivas entre os seres humanos, a não ser aquelas relativas às oportunidades que os sujeitos 
tiveram ao longo de sua vida, experimentando e aprendendo coisas diversas. No fundo havia uma premissa: considerar que as empresas poderiam funcionar em qualquer lugar do mundo, contanto que se considerasse e se respeitasse as diferenças citadas. Por exemplo, não seria prudente se esperar que os prazos para a manutenção de um equipamento fossem os mesmos para uma empresa situada nas vizinhanças dos produtos das máquinas e outra situada a milhares de quilômetros de distância e, possuindo uma malha rodoviária precária e ainda um tecido industrial incipiente.

Os problemas encontrados nos países que importavam tecnologias, assim como os modelos organizacionais, o levaram a questionar os modelos vigentes, principalmente os que diziam respeito às diferenças com relação à inteligência humana, aqueles que preconizavam que os trabalhadores que habitavam em países considerados como não desenvolvidos seriam menos inteligentes que os de países centrais. Tanto é que Wisner propôs que se deveria classificar esse países como em desenvolvimento industrial. Nesse período da história econômica, a ênfase nos estudos na área estavam centrados em transferências que ocorriam, sobretudo, quando as empresas multinacionais no seu processo de expansão transferiam usinas inteiras cuja operação apresentava grandes problemas. Além das usinas, dependendo do local onde se situassem, havia também a implantação de toda uma infra estrutura que também seria construída para permitir o funcionamento das empresas.

6 No caso das empresas consideradas como integrantes do setor de serviços e, mais especificamente no que diz respeito a centrais de atendimento praticamente não houve estudos baseadas nos pressupostos da antropotecnologia. Tal fato se explica provavelmente, devido ao seu desenvolvimento ainda incipiente ou, à pouca mobilidade deste tipo de empresa naquele período.

7 Os trabalhos desenvolvidos no campo da antropotecnologia apontam os problemas resultantes de transferências realizadas sem considerar as características dos locais de implantação, tanto no que diz respeito aos resultados da produção, quanto às relativas à saúde dos trabalhadores. Os mesmos problemas foram encontrados tanto no caso da relação entre países, isto é, quando se tratou da implantação de empresas ou de novos equipamentos, quanto em países considerados em vias de desenvolvimento industrial, no caso de transferência entre regiões distintas no mesmo país (Abrahão, 1986; Negroni, 1986). Encontramos também na literatura referência a alguns estudos sobre a questão no setor agrícola.

8 Os estudos realizados nesse período apontavam para uma questão central associada aos questionamentos sobre os limites da inteligência dos trabalhadores, sua cultura, sua formação e seus saberes. Hoje ainda, encontramos a mesma e falsa questão, malgrado o fato de que as transferências e seus problemas situam-se sabidamente no nível da organização do trabalho, no tecido industrial que determina a capacidade instalada para dar apoio às operações. Foram identificados também problemas relativos aos recursos educacionais oferecidos pelas empresas para propiciar educação formal no domínio das tecnologias, além dos processos de treinamentos, proporcionado nas próprias empresas, principalmente porque muitos desses programas não estavam baseados na realidade aí encontrada, o que se buscava focar teria como base as tarefas, tais como foram previstas nas matrizes. A questão do nível de inteligência está superado, mas o acesso à informação e à educação continua central para o desenvolvimento tecnológico e social na grande maioria dos países. 
9 Nestes quase 30 anos, ocorreram muitas mudanças na economia mundial, discute-se os reflexos da "globalização" e seus possíveis efeitos, tanto no que diz respeito às mudanças que ocorreram na economia, quanto à possível aproximação entre os países, facilitando as trocas, as transferências de empresas, a implantação de técnicas de gestão e de modelos de organização do trabalho. Além disso, o desenvolvimento da chamada "economia de serviços" trouxe novos desafios às maneiras de organizar o trabalho, definir o conteúdo das tarefas, bem como as possibilidades da transferência de empresas e de modelos de produção e de gestão. No que diz respeito a mudanças tecnológicas, as chamadas NTIC (Novas tecnologias da informação e da comunicação) trouxeram mudanças radicais no cenário, uma vez que hoje as possibilidades de troca de informação cresceram exponencialmente, permitindo no caso das Centrais de Atendimento que o trabalho seja controlado à distância e que seja possível implantar esses tipos de operação de serviço em outras localidades, distintas daquelas onde reside a população a ser servida. Há muitos casos em que os atendentes trabalham em outros países se expressando na língua dos clientes.

10 Na literatura encontramos autores que criticam esta separação nítida em serviços e em indústria, uma vez que em qualquer atividade industrial e, mesmo agrícola encontramos nelas partes significativas dos processos que são tipicamente de serviços e, no caso das empresas do setor terciário, encontramos nos seus processos de produção, atividades tipicamente industriais que servem de suporte para a relação com os clientes (Zarifian, 2001 ; Salerno, 2001).

O objetivo principal deste texto é discutir conceitualmente, à luz dos achados em antropotecnologia, as premissas sobre as quais se apoia a gestão em centrais de atendimento. Em particular, as implicações para a linguagem dos trabalhadores relacionadas a este tipo de atividade e também a questão do esvaziamento do sentido, uma vez que, os trabalhadores se vêem, muitas vezes, frente a situações onde praticamente não podem agir e frente a uma visão muito estereotipada do seu trabalho por parte da hierarquia. O seu trabalho é considerado, em muitas vezes como simples e passível de padronização. o desafio é evitar o empobrecimento do conteúdo do trabalho, seja pelas tentativas excessivas de padronizar as tarefas, incluindo a linguagem, os procedimentos rígidos frente às possíveis demandas. Este processo é resultado de uma visão simplificadora na qual a busca de controle hierárquico das ações é uma das tônicas centrais da organização do trabalho. Como consequências, alem da improdutividade e da falta de qualidade sob a ótica do cliente, o sofrimento patogênico vivido pelos trabalhadores se torna parte inerente deste tipo de trabalho.

Acreditamos que estudar as centrais de atendimento no âmbito das disciplinas que estudam o trabalho e com inspiração na antropotecnologia faz sentido, uma vez que na sua operação foram incorporados modelos de gestão e de organização do trabalho oriundos de preceitos de base do taylorismo fordismo mas, com diferenças significativas. O controle do trabalho é feito em tempo real, não há uma sequencia linear de produção, uma vez que se trata de um sistema em que um grande contingente trabalha na linha de frente, sem que haja uma relação direta com as etapas seguintes e, muitas vezes os objetivos quanto à resolução dos problemas dos clientes não estão claros. Todavia, é importante que se esclareça que a referência que aqui é feita não cobre o amplo espectro de empresas com atendimento ao cliente por telefone. Há casos que fogem completamente do que é desenvolvido neste artigo, geralmente quando se trata de serviços considerados pelas empresas, como "profissionais" e não de "massa". 
O desenvolvimento do setor de serviços e dos serviços providos por outros tipos de empresas públicas e privadas trouxe no seu bojo um amplo desenvolvimento das centrais de atendimento pelo mundo. Entretanto, nenhuma ou quase nenhuma inovação foi implantada ou constituída, exceto no caso da incorporação em massa das Tecnologias de Informação e Comunicação (TIC), os modelos organizacionais são simulacros de modelos industriais considerados ultrapassados.

13 Assim, a transferência de modelos e a visão redutora da realidade a um todo que pode ser prescrito e controlado, coloca-se a questão de como os trabalhadores podem desenvolver suas competências, de maneira a constituir um contexto de ação significativo. Este tipo de visão do mundo típico do ideário funcionalista desconsidera as especificidades locais e, também a existência de sujeitos que agem e decidem (Maggi, 2006).

iscutir este tipo de trabalho também advém do fato de que, apesar das diferenças entre países, este tipo de serviço teve um grande desenvolvimento nas últimas décadas. Eles são facilmente transferíveis entre países diferentes ou, até mesmo entre diferentes regiões do mesmo país. Aparentemente os resultados para as empresas têm sido positivos, visto que são poucos os indicares de uma possível reversão de postura. Cada vez mais as centrais de atendimento são deslocadas para outras cidades e outros países, em consonância com os modelos que preconizam a terceirização de partes dos processos de produção.

Outro aspecto significativo diz respeito às conseqüências para a saúde dos trabalhadores, que se manifestam de forma similar independente de sua localização geográfica. Encontramos evidências significativas demonstrando que a maneira como é organizado o trabalho e o conteúdo das tarefas, gera riscos concretos que se manifestam por meio de distúrbios relacionados ao sistema ósteo-muscular, da fala e em elevados graus de sofrimento mental.

contexto internacional, o movimento de redução de custos por parte de grandes empresas estimula o surgimento de centrais de atendimento em países como Índia, México e Filipinas, onde a população recebe baixa remuneração e é fluente em inglês ou espanhol. Sem a vantagem do idioma, empresas brasileiras tentam oferecer custos ainda menores : um atendente brasileiro ganha cerca de um terço do salário de um americano.

17 Alguns indicadores sócio-demográficos dos profissionais de tele atendimento (como também são conhecidas as operações nas centrais de atendimento) no Brasil reforçam o pressuposto de que há desafios importantes colocados pela maneira como são implantadas estas centrais. Em sua grande maioria são jovens (78\% até 30 anos de idade), de perfil predominantemente feminino (70 \%) e de alta qualificação. Apesar dos dados epidemiológicos pouco consolidados, em nossas pesquisas, encontramos altos níveis de afastamento por doenças como as LER/DORT, em algumas situações havia aproximadamente $14 \%$ de licenças médicas entre os trabalhadores de atendimento, além de quase $80 \%$ de queixas de desconforto e dor. Queixas de distúrbios psíquicos também foram importantes, mas não encontramos dados estatísticos a respeito. Pesquisa envolvendo 3.500 operadores franceses de teleatendimento mostrou resultados contundentes, com queixas de ansiedade, estresse e fadiga ( $71 \%$ dos entrevistados), problemas visuais e auditivos (16\%) e dorsalgias (6\%) (CFDT, 2002). Esses dados indicam que o problema não está localizado em um país ou em uma 
empresa, mas que eles se disseminaram e se tornaram significativos para a saúde pública em diferentes países.

Finalmente, podemos acrescentar o fato que, em muitas situações, trata-se de empresas que estão prestando serviço para outras. Por exemplo, ao ligar para uma central de atendimento de uma operadora de cartão de crédito, o cliente provavelmente estará em contato com um trabalhador que é assalariado de outra empresa, que por sua vez presta serviços para a contratante. Esta situação limita as possibilidades do trabalhador encontrar soluções que favoreça o desenvolvimento de estratégias operatórias favoráveis ao seu equilíbrio psíquico e ao cliente na resolução de sua demanda.

19 A implantação de modelos de trabalho com forte inspiração taylorista e fordista desconsidera as características locais, como as maneiras de constituir relações, inclusive as relações de serviço, pois os pressupostos que compõe esta visão de mundo, propõem a simplificação de tarefas, determina procedimentos muito restritivos para as ações dos indivíduos, inclusive para o diálogo entre os atendentes e os clientes.

$\mathrm{Na}$ base destes pressupostos subjazem as restrições de linguagem; as pessoas se vêem obrigadas a se comunicarem segundo uma racionalidade oriunda do prescrito pelas organizações. Para tanto é necessário enquadrar a linguagem do atendente e a dos clientes àquela prevista pela empresa. Portanto, é necessário mediar linguagens ; de um lado a linguagem coloquial do cliente e, de outro, a linguagem informática e técnica, prescrita e codificada. São as competências elaboradas pela via dos processos cognitivos, sobretudo, da memória do operador que vão permitir que o diálogo seja inteligível para o usuário e, ao mesmo tempo, ágil e correto tecnicamente, com registros adequados no sistema informático. As consequências são significativas com relação ao empobrecimento das trocas, à dificuldade ou mesmo a impossibilidade de constituição de uma cultura de profissão, levando a uma possível perda do sentido do trabalho e, mesmo perdas em produtividade e qualidade na produção.

21 Este tipo de situação pode levar a paradoxos significativos, uma vez que ao se tratar de um trabalho amplamente ancorado na comunicação verbal, portanto, dependente da riqueza da fala e da possibilidade de construção de um diálogo eficaz e cordial, muitas vezes, os trabalhadores se vêem na obrigação de tergiversar, senão mentir, uma vez que não tem o que dizer ao cliente, pois estariam agindo contrários às prescrições, em detrimento dos interesses mais imediatos da empresa, definidos pela hierarquia.

Nesse artigo são analisadas diferentes dimensões relativas ao trabalhar em centrais de atendimento identificando as dificuldades que os atendentes enfrentam para responder às exigências da produção, em situações nas quais as tarefas foram concebidas, a partir de paradigmas sustentados por princípios simplificadores da realidade da produção de serviços e do trabalho humano. A perspectiva da implantação de centrais de atendimento em diferentes localidades, dispersas em diferentes países e regiões de um mesmo país convoca uma análise baseada não apenas na ergonomia da atividade, mas também em princípios da antropotecnologia, em diálogo com a psicodinâmica do trabalho.

\section{Estudos em centrais de atendimento}

Essa discussão é fruto de aproximadamente uma dezena de estudos desenvolvidos por duas equipes de pesquisa, do Departamento de Engenharia de Produção da Escola 
Politécnica da Universidade de São Paulo e do Núcleo de Ergonomia Cognitiva e Saúde do Instituto de Psicologia da Universidade de Brasília. Esses estudos foram realizados em Centrais de Atendimento ligadas ou contratadas por diferentes tipos de empresa : bancos, empresas de cartão de crédito, empresas de telecomunicação, serviço público. Os estudos foram desenvolvidos na cidade de São Paulo e em Brasília.

As demandas para o desenvolvimento desses estudos estavam associadas a problemas de saúde, em sua maioria, Distúrbios Ostéo-musculares Relacionados ao Trabalho (DORT), conhecidos também como Lesões por Esforços Repetitivos (LER). Ressalte-se que, em quase todas as situações estudadas, o objetivo principal das empresas era o de reduzir os problemas de saúde crescentes nas Centrais de Atendimento sem que houvesse, de fato, a intenção de transformar profundamente os processos de produção e o conteúdo das tarefas. Havia sim, uma disposição para tratar de aspectos parciais da questão, como o mobiliário e o sistema de pausas.

Os métodos adotados nesses estudos permitiram um diagnóstico aprofundado das questões ligadas ao trabalhar e as suas conseqüências para a saúde dos trabalhadores, para o seu desempenho e para o seu desenvolvimento profissional. Esses resultados trazem à tona um debate interessante relativo às intenções dos atores sociais na empresa com relação à efetividade das mudanças. Eles apontam ainda problemas significativos ligados ao projeto do trabalho, o que poderia ser reapropriado pelos trabalhadores na perspectiva de um projeto de reformulação profunda do conteúdo das tarefas e da organização do trabalho. Mas de fato, malgrado o quadro alarmante de adoecimento, na maioria das centrais estudadas tanto na modalidade de atendimento passivo quanto ativo, o modelo da organização do trabalho se mantém vinculado aos princípios propostos por Taylor no século passado. Nesse sentido, a questão que se coloca neste artigo é : em que medida esses princípios contribuem para o quadro de adoecimento comum a maioria dessas empresas?

Os métodos de análise adotados nesses estudos se inspiram na Análise Ergonômica do Trabalho - AET (Guérin, Laville, Daniellou, Duraffourg \& Kerguelen, 2001) e na Ação em Psicodinâmica do Trabalho (Dejours, 2004). No caso da AET, buscou-se levantar dados relativos à tarefa e seus determinantes. Para tanto foram, realizadas entrevistas com gestores, supervisores diretos, projetistas dos sistemas de produção, responsáveis pela gestão e implementação de sistemas de informação, responsáveis pelos sistemas de qualidade e, também com profissionais da área de propaganda e venda. Além das entrevistas, buscou-se dados secundários relativos aos procedimentos operacionais, "scripts", manuais de qualidade, e aos dados de produção. Também levantou-se dados demográficos, incluindo idade, sexo, escolaridade, senioridade e, dados epidemiológicos obtidos junto aos serviços de saúde das empresas. Em três delas realizou-se um levantamento junto aos trabalhadores visando identificar sintomas de desconforto ou dor vivenciados por eles. Cada estudo teve suas peculiaridades principalmente no que diz respeito à disponibilidade dos dados existentes nas empresas. Entretanto, em todas elas foi possível obter dados bastante significativos que propiciaram a construção dos problemas identificados nas tarefas e que puderam nortear as observações e as análises das atividades. A partir da análise das tarefas que propiciaram a construção das primeiras hipóteses relativas à gênese dos problemas de saúde, foram realizadas observações abertas e sistemáticas da atividade de trabalho. Uma outra questão metodológica importante foi o envolvimento dos trabalhadores. Em todas as situações, houve acompanhamento de trabalhadores e, em parte dos estudos foram criados 
grupos com trabalhadores voluntários nos quais se discutiu questões ligadas ao seu trabalho buscando revelar a ação dos trabalhadores. Eles se envolveram em processos de validação dos resultados e na construção das propostas de melhorias

No caso da Psicodinâmica do Trabalho (PDT), trabalhou-se com grupos de expressão (Dejours, 2004) com o objetivo de criar um espaço de discussão visando favorecer a troca de experiência entre os trabalhadores participantes. Nesse percurso, buscou-se a construção de um sentido comum sobre o trabalhar e a re-apropriação por parte de cada membro do grupo da sua história e da sua experiência, muitas vezes dolorosa e com sequelas. Para a constituição desses grupos, fato que ocorreu em três empresas, propôs-se aos trabalhadores, numa palestra inicial, em que participaram todos os integrantes das centrais de atendimento, a possibilidade de constituir grupos de voluntários para o desenvolvimento da proposta de ação. Esses grupos se reuniram regularmente (a cada sete ou quinze dias), totalizando entre 18 e 24 horas de reuniões. Ao final, um documento foi discutido e validado com os participantes, antes de ser entregue à empresa e aos participantes para que pudessem receber o resultado do trabalho desses coletivos de expressão.

Assim, os estudos nos quais este artigo se apóia adotaram nos seus procedimentos tanto uma abordagem de natureza quantitativa quanto qualitativa. Essa opção se deve sobretudo, a possibilidade de qualificar os dados de natureza quantitativa explicitando dimensões subjetivas do trabalho para as quais a abordagem quantitativa se mostra lacunar.

29 Não é o propósito desse artigo detalhar cada estudo e os resultados obtidos. O que se pretende é uma reflexão consubstanciada apoiada nesses resultados. Assim, a estrutura foi delineada a partir da compreensão das situações analisadas e que podem contribuir nas reflexões dos projetos e no gerenciamento diferenciado das situações de trabalho em centrais de atendimento.

30 Malgrado a diversidade geográfica e das situações de trabalho que subsidiaram este artigo além, da temporalidade entre elas, a articulação dos diferentes resultados só foi possível devido ao constato que, embora, a tecnologia tenha passado por mudanças estruturais as contingências pouco evoluíram.

\section{Uma discussão baseada nos resultados dos estudos}

\subsection{As contradições : fontes de problemas de produtividade e de qualidade?}

31 As diferentes racionalidades que orientam o projeto da produção e das tarefas, assim como a gestão da produção e do trabalho, nas centrais de atendimento nem sempre são coerentes. Muitas vezes, aqueles que prescrevem não estão em sintonia com o real do trabalho que se impõe para o atendente, uma vez que a prescrição e as restrições que eles tem com relação à sua alçada para agir pode ser incompatível com a demanda colocada pelo cliente. $O$ respeito ao prescrito, isto é as regras de atendimento são as bases para avaliação do trabalho dos atendentes.

32 Se nos ativermos apenas ao que diz respeito à racionalidade técnica, identificamos entre os diferentes estudos que dão sustentação a este artigo, dissonâncias 
significativas entre as áreas de produção do atendimento ao cliente, especificamente as centrais de atendimento, com outros setores, como vendas, marketing, crédito. Ações empreendidas em outros setores impactavam de forma significativa na linha de frente do atendimento, por falta de concertação anterior e preparação das operações. Ao dirigir a questão para a interface entre o cliente e o atendente identificamos conflitos, pois em muitas situações, o cliente não aceita e não entende o que foi definido pela empresa como ação possível e o que seria passível de ser solucionado ou encaminhado para a buscas de soluções. Em situações como estas, muitas vezes, os próprios operadores não concordam : ora com a empresa, ora com os clientes, no entanto, o seu papel seria o de mediar o conflito resultante de duas racionalidades distintas, muitas vezes sem ter os elementos necessários para atingir este objetivo.

Não é possível prescrever os procedimentos que se encaixem em todas as situações com as quais os atendentes são confrontados, assim eles buscam desenvolver estratégias para responder de maneira apropriada ao cliente e manter a atividade em um nível satisfatório tanto para eles quanto o que foi previsto pela organização. 0 desenho do script não considera o contexto de atendimento, a variabilidade e a diversidade dos usuários e dos clientes. No entanto, para efetivamente atender ao cliente, decodificar o script para tornar compreensível a sua resposta à demanda do cliente o atendente se vê obrigado a transgredir (Abrahão \& Torres, 2004). Essas transgressões, ou ações que possibilitam um desempenho mais adequado e, quiçá, menos sofrimento ficam escondidas, camufladas, condenadas aos porões, uma vez que ao desrespeitar o prescrito, elas não podem ser reconhecidas oficialmente.

34 A realidade das centrais tem mostrado uma organização pouco ou nada flexível: flexíveis são os trabalhadores. As diferentes formas de transgressões mostram que seria importante rever os conceitos, uma vez que a busca desenfreada para simplificar as tarefas sem considerar a realidade, levam a impasses que só são resolvidos na surdina.

As situações de atendimento são cheias de imprevistos, de dificuldades para se compreender a demanda do cliente e sobretudo para, entender o seu problema e buscar soluções. Este tipo de situação requer do trabalhador habilidades, experiência para prever, equacionar e decidir para fazer frente a estes imprevistos (Sato, 2002). Se por um lado a realidade é rica, os procedimentos, mesmo que sejam inúmeros e detalhados, não permitem que se dê conta da realidade, mesmo que os processos sejam considerados simples e repetitivos. Neste sentido, dever-se-ia permitir uma margem de decisão para que os operadores pudessem construir situações de trabalho propícias para dar conta de tal demanda. Como o prescrito vai de encontro a esta perspectiva, em muitas situações, os trabalhadores se sentem "robotizados", pois não podem agir, não podem responder, não podem resolver. Em outras situações, paradoxalmente, para se defenderem da ira dos clientes e da sua impossibilidade de agir, se fazem passar por "máquinas", respondendo como se fosse uma gravação, enfim uma estratégia para evitar maiores dificuldades e problemas com clientes, mesmo que esta postura seja discrepante com o prescrito.

36 A tarefa é definida por um grande número de normas, procedimentos, atitudes e responsabilidades prescritas, que o atendente deve seguir. Muitas delas são importantes e na maioria das vezes, respeitadas pois ajudam a garantir a segurança da operação. Outras são restritivas, pouco compreendidas, podendo ser caracterizadas como normas de conduta pouco adequadas pela impossibilidade de adaptação das prescrições à realidade da demanda dos usuários. 

local de implantação das centrais diz respeito ao conteúdo restritivo das tarefas. Esse procedimento traria consequência com relação à linguagem e, mesmo com relação à riqueza do pensamento ? Algumas evidências mostram que há um empobrecimento da linguagem, uma vez que é frequente o uso do gerúndio pelo atendente, ao tentar explicar ao cliente uma ação que deverá ser encaminhada pela empresa, que ele sabe que raramente haverá continuidade. $\mathrm{O}$ uso abusivo do gerúndio teria como causa a indefinição quanto às possibilidades de agir e, também poderia ser o resultado de um tradução mal feita do inglês, usado muitas vezes como referência para a construção dos scripts.

Como fazem os trabalhadores para "funcionar" nesse tipo de contexto e responder aos requisitos citados. A despersonalização do agir no trabalho, a falta de poder para agir, o individualismo, são pilares desta lógica que leva ao sofrimento patogênico, no sentido proposto por Dejours (2001) ; sofrimento que se torna "visível" no sistema músculo esquelético, na pele, no sistema digestivo, entre outros; ou, ainda expresso como distúrbio psíquico. Esse tipo de produção "em massa" de serviços seria uma repetição de certos erros do passado ? Ou seria ainda pior, uma espécie de farsa uma vez que a prestação de serviços constitui uma relação entre sujeitos e a sua despersonalização se torna uma das causas fundamentais de sofrimento para os trabalhadores?

\subsection{Uma síntese da atividade nas centrais de atendimento}

39 As diferentes organizações responsáveis pelas centrais de atendimento pressupõem que a relação de serviço entre o atendente e o cliente seja restrita ao diálogo definido pelos projetistas do serviço e, que desvios da norma, sejam combatidos, pois por princípio fogem da estratégia de atendimento definida pela empresa. 0 cliente não pode solicitar o que não está previsto, mesmo que ele não saiba, e o atendente deve responder da maneira mais próxima ao padrão estabelecido e prescrito. Diferentemente da prescrição taylorista fabril, em que o objeto central é o modo operatório, neste caso, a prescrição está centrada no que seria possível dizer, um simulacro de diálogo. Assim o que se busca padronizar é a linguagem, parte significativa das atividades relacionais humanas.

40 Com esta pretensão, não importa com quem o atendente está falando, ele deverá ser treinado para dirigir o cliente para o diálogo previsto e, as palavras a serem utilizadas devem ser as mais precisas, na ótica de quem prescreve, para evitar possíveis mal entendidos. Frases pré-definidas para explicar o que se passa ou para efetuar uma determinada operação seriam, portanto, fundamentais para garantir a qualidade de atendimento buscada pelos projetistas e pelos organizadores do trabalho.

41 Trata-se de uma pretensão intrigante, sobretudo se considerarmos que os objetivos não se restringem apenas a enquadrar o atendente, o "operário não qualificado de atendimento", mas também o cliente, que deverá agir conforme previsto para evitar conflitos e assegurar que o serviço previsto seja prestado. Nesse contexto nos encontramos em face de um grande paradoxo e de uma distância significativa entre o projetado e a realidade.

42 Esta contaminação do setor de atendimento por modelos de gestão atualmente questionados no mundo industrial se torna ainda mais grave, pois nesse caso, a linguagem é uma das mediadoras do processo produtivo. A disseminação de frases 
idênticas, independente do usuário, ignora que a linguagem é uma das expressões mais significativas da cultura das populações. Em primeiro lugar, a prescrição da fala, pressupõe que o diálogo seja construído de uma determinada maneira, como se as frases sucessivas fossem semelhantes às operações de montagem de um determinado produto. Ainda mais, supõe-se que a simplificação facilite o entendimento e que, eliminando a redundância, por exemplo, se ganha tempo e impede-se que o diálogo se estenda. Um diálogo só faz sentido quando permite a aproximação de pontos de vista, o que só é possível se forem respeitadas as posições diferenciadas e, que se permita compreender o que o outro fala, isto é, que haja espaço para a escuta do outro.

Uma série de instruções e imposições com relação à tonalidade da voz, linguagem, tratamento ao cliente, cadência do diálogo, ações e expressões a serem evitadas pelos atendentes estão presentes e foram descritas em artigo de Mascia e Sznelwar (1998). Os autores constataram que as instruções se referem somente às situações conhecidas ou previstas, portanto, não comportam a diversidade de ocorrências que os atendentes se deparam no cotidiano de atendimento.

Seria esta uma das principais fontes de sofrimento para os atendentes, e causas dos problemas de saúde encontrados nesta população, além de ser um dos fatores que contribuiriam para perdas em qualidade e também em produtividade? Vale salientar que os problemas de saúde encontrados em nossos estudos eram, em parte reconhecidos pelas empresas, mesmo que ao se discutir sobre as possíveis causas relacionadas às escolhas organizacionais, havia uma negação explícita, muitas vezes imputando esses problemas a uma certa "fragilidade individual". Todavia, questões ligadas à qualidade, principalmente com relação à percepção do cliente com relação ao atendimento, não eram considerados como sendo fatores determinantes para gerar mudanças nos processos de produção e na divisão do trabalho, uma vez que eram considerados satisfatórios, tendo em vista as estratégias comerciais e de produção. A questão da produtividade também não era considerada um problema, uma vez que os principais indicadores mediam apenas os tempos de atendimento e a quantidade de pessoas atendidas ou que deixaram de sê-lo. Não foram encontrados, em todos os estudos desenvolvidos, indicadores que permitissem avaliar a quantidade de problemas resolvidos, em quanto tempo e após quantas ligações, corolários do tempo de atravessamento em uma linha de montagem industrial. Esses indicadores poderiam demonstrar ineficiência e ineficácia nos processos de produção e, sobretudo os procedimentos adotados.

A inadequação entre o script e a natureza da atividade de atendimento, é reforçada pelo fato dos operadores atenderem a uma variabilidade muito grande de clientes, consequentemente uma alta demanda de processamento de informações. Eles têm que entender e decodificar adequadamente a demanda seguindo a racionalidade do cliente e responder segundo a racionalidade técnica imposta pela empresa, muitas vezes sob pressão temporal, pois o cliente quer uma resposta imediata e o tempo de ligação deve responder às metas estabelecidas. Além disso, nem sempre o cliente tem clareza do que quer, e o atendente é confrontado a procedimentos rígidos sem autonomia para se afastar das prescrições. Assim, a adoção rígida do script é também problemática para o desempenho do atendente e o sucesso da interação. Agir segundo a prescrição seria semelhante a uma "operação padrão", uma vez que, paradoxalmente o trabalhador ao se ater exclusivamente ao prescrito, deixaria de zelar pelo bom andamento do processo 
de atenção ao cliente, deixaria de constituir uma relação de serviço mais cordial e efetiva. raciocínio linear e previsível, uma vez que não agrega e nem deixa espaço que permita articular as possíveis variáveis da situação encontradas na realidade. Portanto, as principais queixas dos atendentes com relação ao controle do script foram quanto a sua rigidez, pois o diálogo acaba se tornado "robotizado" e mecanizado, eliminando o sentido do trabalho, tipicamente um processo de reificação. A maioria dos atendentes apesar destas queixas não quer a eliminação do script e sim, a sua flexibilização (Zimmerman 2005). Eles querem que ele sirva como um roteiro, como um orientador do atendimento. Estes resultados caminham no mesmo sentido dos encontrados por Gubert (2001) no qual uma parte dos operadores vê o script como um componente negativo do controle, enquanto outros apontam aspectos positivos citando-o como um orientador e um auxiliar para o atendimento.

A padronização é rígida e influencia a maneira de falar, determina o que se pode dizer, e também o que não se deve dizer, é um diálogo prescrito (Sznelwar \& Mascia 2000 ; Zimerman, 2005). Esses estudos demonstram que os atendentes, ao seguirem rigorosamente o script, muitas vezes, não conseguem construir um diálogo verdadeiro, não conseguem entender e se fazer entender pelo cliente. Devido ao controle rigoroso da monitoria eles se sentem impedidos de usar a criatividade para construir um diálogo mais espontâneo e natural. Entretanto, alguns atendentes mesmo correndo o risco de serem penalizados na sua avaliação fazem alterações para adequarem o contato ao perfil do cliente (Torres, 2001). A monitoração acaba sendo na maioria das centrais, uma via de mão única e, segundo os atendentes elas se tornam avaliações onipotentes, que além de gerar atitudes antipáticas causam insegurança e sentimento de injustiça pois pode servir como uma imposição na qual não existe espaço para a negociação.

Ainda mais porque o colega, a pessoa que está mais próxima de mim, é alguém com o qual não se pode contar pois a maneira como o trabalho é organizado induz à competição, à necessidade de sobrepujá-lo. Isto pode levar à banalização de certas práticas pois o sistema não favorece, aliás combate a cooperação. Assim o que emerge é aquilo que há de mais nefasto no trabalho, ao invés de favorecer os seus aspectos positivos. Assim, segundo Dejours (2008) "o resultado final da avaliação e dos dispositivos conexos é principalmente a profunda devastação dos níveis de confiança, do viver-junto e da solidariedade, isto traz efeitos diretas na construção da sua cultura, pois suas bases estariam sofrendo um processo de distorção" (p.233). Assim, haveria um reforço da perspectiva do individualismo em detrimento do que há de coletivo no trabalho, fato que traria no seu bojo conseqüências significativas favorecendo uma crescente incidência de sofrimento patogênico (Dejours, 2009).

Outra inadequação refere-se à pouca margem para dar conta da variabilidade presente nas situações de atendimento. A rigidez dos procedimentos e as restrições temporais deixam muito pouca margem para os atendentes adequarem o atendimento às necessidades dos clientes. Existe uma variabilidade muito grande de clientes quanto à idade, sexo, grau de instrução, estado civil e estado de origem. Eles utilizam linguagens distintas na comunicação. Cada atendente também é portador de uma história com características próprias, experiências, vivências. É neste cenário real que a atividade se desenvolve e não naqueles previstos pela organização (Abrahão, 2000). O que se observa 
no dia a dia é que a estabilidade dos manuais e normas não corresponde ao real, pois no trabalho ocorrem variações contínuas.

Contrariamente às profissões mais tradicionais, neste caso, há o risco de ocorrer um empobrecimento da linguagem ao invés da criação de uma "linguagem de ofício" ou ainda, a possibilidade de enriquecer, pela via do trabalho o vocabulário. No que diz respeito à qualificação dos trabalhadores a opção é treinar os atendentes no aprendizado de certas técnicas que ajudem a manter o cliente e o atendente no prescrito. Isto é, dentro do previsto para a concepção do sistema técnico, que se concretiza nos procedimentos de fala e nos procedimentos de navegação previstos nos programas de computador.

51 Esta condição é um dos pontos nefastos da prescrição nesse tipo de trabalho, pois abre espaço para mal-entendidos, punições, avaliações negativas, em suma, pode ser um fator agravante para o sofrimento dos trabalhadores, pois a sua iniciativa não é reconhecida, não se torna parte de um conhecimento coletivo. Esta fonte de sofrimento para os atendentes, pode ser considerada como uma das principais causas dos problemas de saúde encontrados nesta população e também como um dos fatores que contribui para perdas em qualidade e em produtividade.

Ao que tudo indica, a maneira como o trabalho é organizado nas centrais de atendimento prejudica o desenvolvimento do trabalhador ainda mais, por que não propicia espaços significativos para trocas e para a cooperação entre pares que facilitaria a criação de um quadro de referência compartilhado, composto por modelos de situações bem sucedidas nas operações. $O$ conteúdo das tarefas impede a expansão do campo das ações, fundamental para desenvolvimento profissional individual e coletivo desta categoria de trabalhadores. Em nenhuma situação estudada foram encontrados espaços de troca, onde se pudesse praticar em conjunto atividades para facilitar o retorno da experiência, enriquecendo os conhecimentos e o repertório dos trabalhadores com relação às situações vividas.

Podemos observar que parte significativa dos problemas identificados, resultam da implantação de tecnologias que trazem consigo um pacote normalizado com determinações referentes à organização do trabalho que tratam de forma homogênea o ato de trabalhar. Assim, a lógica é a mesma adotada na implantação das usinas nos casos de transferências de tecnologia nos estudos relatados pela antropotecnologia no século passado.

\subsection{Outras questões associadas ao trabalhar}

54 A busca frenética por um certo tipo de produtividade, a luta constante contra os "tempos mortos" teria como fruto uma compressão progressiva dos tempos e, uma conseqüente "contração dos corpos". Alguns resultados obtidos nesses estudos mostram uma correlação entre a redução de tempos médios de atendimento (TMA) e o aumento significativo de afastamentos por LER/DORT (Mascia \& Sznelwar 1998) .

Coerente com essa visão de mundo mecanicista e funcionalista (Maggi, 2006), os atendentes são considerados pelas empresas, apenas receptores de chamadas, sem possibilidade de agir além do que lhes foi prescrito, tipicamente um processo de reificação dos sujeitos. Essa mesma lógica de funcionamento está presente nas diferentes centrais de atendimento distribuídas pelo mundo. Para as organizações qualquer transformação no processo de trabalho, ou mudanças nos procedimentos deve 
ser fortemente combatida, uma vez que o modelo que traz resultados é esse mesmo, qualquer outra forma de organizar o trabalho seria considerado como portador de alto grau de incerteza e, traria no seu bojo o risco de prejuízos financeiros significativos. Reduz-se essa situação, a uma atividade normalizada de interação entre o atendente e o cliente, não importando quaisquer aspectos da variabilidade dos clientes, das regiões, dos países. Assim, há uma tentativa de homogeneizar os modos de atender, ao contrário de se considerar a heterogeneidade, privilegiando a diversidade, considerando os contextos do sistema de uso e de produção.

Essa situação remete, como ressalta Dejours (1987) aos primórdios dos estudos da psicopatologia do trabalho, realizados por Le Guillant e sua equipe $(1956,2006)$, sobre as telefonistas. $\mathrm{O}$ autor afirma que estas profissionais devem reprimir suas iniciativas, enquadrar sua linguagem, não apresentar qualquer expressão de cansaço, não se irritar, não expressar descontentamento ou ainda prazer diante de uma situação de atendimento. Nessas condições a sua afetividade deveria então, ser proscrita. Considerando que os atendentes devem ser simpáticos a sua afetividade seria também alvo de prescrição?

Wisner (1994) também comenta esses estudos, sobre a neurose das telefonistas. Ele aponta a contradição entre a tarefa muito rígida imposta às trabalhadoras e as dificuldades que se manifestam no momento do atendimento. A relação de serviço criada é dificultada, pois o diálogo com o cliente não é favorecido. $O$ cliente precisa entender a racionalidade da empresa, se enquadrar naquilo que é previsto. Ele precisa se expressar usando uma linguagem compatível com a da empresa, ele também, tem um comportamento prescrito que deve ser enquadrado, portanto, precisa ser educado para receber o serviço. Neste cenário, numa relação como esta o cliente deveria, por principio, ser considerado como co-produtor do serviço.

Nesta perspectiva, é importante se distanciar de explicações simplificadoras dos fenômenos ligados ao trabalhar. As atividades em centrais de atendimento não se resumem ao simples gesto, à execução do previsto, ao respeito dos procedimentos, enfim a uma fala prescrita. Há uma questão irredutível que é a relação com o outro, com o cliente que atua e modifica as tarefas.

Outra questão importante a ser considerada com relação às atividades de serviço discutida por Hubault (2003) é a dificuldade de se mensurar a produtividade. Como medir a relação insumos/resultados, principalmente porque os serviços são, em grande parte intangíveis. Para esse autor, a relação de serviço contém uma série de características que são dificilmente valorizáveis por uma produtividade que é medida por meio de indicadores que não consideram esses aspectos. Como avaliar a utilidade do trabalho se a sua essência é desconhecida ? Assim este tipo organização do trabalho não contribuiria para a saúde dos trabalhadores e para a qualidade do trabalho, uma vez que não estaria na perspectiva o atendimento aos interesses dos clientesconsumidores, nem a criação de uma relação de serviço mais construtiva e que perdure (Hubault \& Bourgeois, 2001).

Na mesma linha de pensamento, não se pode deixar de lado uma reflexão sobre a natureza do controle exercido sobre o trabalhador. 0 trabalho de atendimento, mesmo que seja mediado por telefone, implica uma relação intersubjetiva. Conforme apontado somos confrontados a paradoxos significativos nesse tipo de produção. Ao mesmo tempo em que se busca, por meio dos paradigmas da simplificação, uma homogeneidade no atendimento, pede-se ao trabalhador que seja envolvente, 
simpático, carismático, cordato e ainda sob pressão de tempo. Como vários trabalhadores afirmam, eles vivem com uma sensação de se tornarem robôs. Como trabalhar esse paradoxo e construir sistemas de produção em que o relacional não seja objetal?

61 Poderíamos imaginar que o constrangimento gerado pelo não fazer poderia ser considerado como um efeito secundário, não buscado na forma de conceber o trabalho, mas não é bem o que foi encontrado na literatura. O paradigma da simplificação é aquele que se impõe no projeto do trabalho. De fato, o que os departamentos de engenharia e métodos buscam é tornar o trabalho o mais simples possível, passível de ser definido por regras e procedimentos precisos. Desta forma o resultado obtido nas prestações de serviço ao cliente seria mais confiável uma vez que é possível definir, a priori o que se espera.

Apesar de legítima a busca da confiabilidade no serviço, o paradigma da simplificação da tarefa é falso. A questão que se coloca, é que, além do fato que na execução da tarefa existirá uma quantidade significativa de eventos não previstos, que modificam a tarefa, o sujeito se vê obrigado a restringir a sua ação. Qual esforço deve ser produzido para que o trabalhador consiga construir o não fazer. Um exemplo deste não fazer pode ser aquela situação, frequente, em que o trabalhador sabe o que poderia fazer para resolver o problema do cliente, mas ele não pode, pois não está autorizado.

Uma das consequências deste "desengajamento" das empresas com relação ao trabalho considerado eufemisticamente como de execução, da manufatura dos objetos e de determinadas partes do processo de produção de serviços pode ter reflexos profundos sobre a economia psíquica dos sujeitos. Será que, como afirma Sennett (2001), estaríamos vivendo o cenário ideal da corrosão do caráter, em que as relações estáveis, de fidelidade, estariam sendo substituídas por relações voltadas para o interesse imediato, para a garantia da dita "empregabilidade", na qual cada um seria responsável também por seu futuro? Faria parte deste cenário, o desengajamento crescente do Estado com relação aos benefícios sociais, mais um triunfo do processo de financeirização das relações? Nesta mesma perspectiva, não estaria sendo favorecido um cenário de "vale-tudo", semelhante ao que Dejours (1998), discute sobre a perspectiva da "banalização" das ações nas empresas, em que a relação com o outro seria determinada por interesses e o ato de infringir o "mal" a alguém faria parte do jogo? Ressalte-se que a individualização de tudo que ocorre nestas situações de trabalho, uma vez que tudo dependeria de um só atendente, a relação com o colega, em um processo de trocas horizontalizado, não se faz necessária para dar encaminhamento aos processos ; aliás as trocas são consideradas como nefastas pois atrapalham o colega e tem impacto na busca de bater as metas individuas. Todo o processo de controle, de punição e de recompensa também é individualizado. Neste cenário o que mais se propicia é a competição entre os pares, os espaços de cooperação, de ajuda mútua, de construção de regra de ofício compartilhadas é muito restrito, senão inexistente.

64 A atividade dos atendentes que é basicamente de relação, poderia se tornar uma âncora fundamental para o desenvolvimento das ações. No entanto, a prescrição atinge diretamente aspectos do comportamento considerado como aceitável e produtivo com relação ao desempenho do setor. Questiona-se até que ponto tudo pode ser prescrito e se é produtivo fazê-lo. Há uma diferença significativa entre a adoção de condutas cordiais em que o atendente possa efetivamente responder à questão do cliente, condição que pode e deve ser favorecida e estimulada pelas empresas e, um 
comportamento estereotipado, restrito a ações padronizadas, no qual a possibilidade de desenvolver estratégias para resolver problemas e para acompanhar o processo de atendimento ao cliente de uma maneira mais efetiva não é prevista, sendo mesmo combatida, proibida. Ainda a criação de espaços de deliberação sobre às regras da profissão deveria ser considerada, principalmente em relação às novas maneiras de se tratar os processos de atendimento, nos quais a tônica seria a resolução efetiva dos problemas agregada a equipes com grau significativo de discricionariedade.

\section{5. À luz da antropotecnologia...}

A antropotecnologia teria um ponto de vista a respeito das questões levantadas neste artigo ? Acreditamos que sim, aliás seria bastante provável que o próprio Alain Wisner, se estivesse vivo, seria um entusiasta visando o desenvolvimento de estudos sobre esses processos de transferência de empresas e de modos de concepção de organização do trabalho. Os efeitos nefastos com relação a este modo de transferência de tecnologia já foram discutidos neste artigo, chama a atenção alem dos problemas de saúde mais evidentes e das possíveis perdas de qualidade e de produtividade, o risco de empobrecimento da fala e dos próprios processos de pensamento. Trabalhar sob uma rígida imposição com relação ao diálogo pode trazer distorções significativas com relação a esses aspectos. Um deles seria o de buscar enquadrar tanto os trabalhadores quanto os clientes em uma racionalidade técnica traduzida em uma linguagem prevista apenas naquilo que está explicitado nos scripts. Isto se reflete nos processos de treinamento, onde em várias situações os trabalhadores se viam frente a proposta de "programação da linguagem" e não na busca de enriquecimento cultural para que pudessem melhorar sua capacidade de entendimento e de construção de diálogos. Fica evidente que o sistema proposto é coerente com a simplificação e o empobrecimento, colocando em risco o desenvolvimento profissional e pessoal desses trabalhadores.

Contrariamente a essas premissas, Wisner (1997) adotou conceitos oriundos do pensamento de Vygotsky para ajudar a pautar os aspectos centrais da antropotecnologia, em especial para colocar em perspectiva as possibilidades de transformação desses modelos visando facilitar a concepção de sistemas de produção em que se que valorizasse as culturas locais. Enfim, buscando a construção de processos que favorecessem o enriquecimento e não o empobrecimento cultural. Neste texto, nos apoiamos nesta discussão para entender o que se passa nas atividades de serviço, as consequências da adoção e implantação de modelos de atendimento que desconsideram tanto a realidade da atividade de relação entre os trabalhadores e os clientes, como a negligência de certas especificidades locais ligadas à cultura, a adoção de novas de tecnologias e, mais especificamente, questões relativas à linguagem.

67 Ainda com relação ao diálogo de Wisner com os conceitos propostos por Vygostky, a riqueza dos processos psicológicos são o produto de uma evolução sócio-cultural e histórica que se constituem antes no plano social para, em seguida, serem incorporadas no plano psicológico. Isto é, são inicialmente uma categoria interpsicológica para depois se tornar uma categoria intrapsicológica. Esta afirmação nos coloca frente a outro dilema: Nos locais de atendimento estudados, a maneira como é organizado o trabalho e o próprio conteúdo das tarefas, impede uma troca maior entre os diferentes atendentes e, mesmo a construção de um diálogo mais rico com os clientes. Então, o substrato que os atendentes têm para a construção de uma linguagem oriunda deste 
trabalho é, em grande parte, resultante do que racionalidade técnica das empresas considera como relevante. $O$ que provém da realidade do atendimento e, mesmo da história pessoal dos clientes e dos atendentes não é integrado ao ato de trabalhar. Além disso, as trocas de experiência entre colegas são quase impedidas pela maneira como é concebido o trabalho resultando na falta de espaço para o desenvolvimento de uma cultura de atendimento, que ajudaria no enriquecimento mútuo, e na constituição de um verdadeiro coletivo de trabalho.

Wisner buscou também apoio na Teoria da Atividade proposta por Leontiev, modificada por Engeström visando adaptar sua aplicação em contextos empíricos. Assim, nossa aproximação com a antropotecnologia pressupõe que, no caso da transferência da tecnologia, é de fundamental importância que os trabalhadores em países considerados em vias de desenvolvimento industrial possam adquirir competências suficientes para responder as exigências da produção, mesmo em situações degradadas e naquelas em que a transferência ocorre de forma parcial. Operar nessas condições implica para o trabalhador uma ampla capacidade de mudar de registro segundo as circunstâncias, que são menos previsíveis em situações de produção mais estabilizadas como mostram inúmeros estudos em ergonomia da atividade. Essa passagem da operação prescrita a uma ação situada que os estudos ergonômicos mostraram as dificuldades e os esforços criativos para dar conta do real, nos casos estudados pela antropotecnologia, envolve ainda mecanismos mais amplos uma vez que, se busca, nos processos de transferência do modo de produção nas centrais de atendimento, uma homogeneização, isto é, numa perspectiva contrária propiciando poucos recursos para os trabalhadores desenvolverem uma atividade enriquecedora.

A implantação maciça no setor de serviços da tecnologia da informação agregada a modelos de gestão semelhantes, se manifesta na atividade de trabalho, propiciando condições de trabalho inadequadas. Além disso, a transmissão de informação pela voz inclui ferramentas que são de natureza psicológica, dentre elas as diferentes formas de linguagem. Desta forma, cada vez que o sujeito incorpora estas ferramentas no seu comportamento, ocorre uma transformação nos processos mentais, que deveriam ser facilitados por estas novas maneiras de mediação. Esses processos comunicacionais são baseados em duas vias, a de quem emite e de quem recebe e isto ocorre nos dois sentidos. Assim sendo os processos constituídos por atividades de diálogo devem considerar sempre que, para enriquecê-los a que se deixar espaço suficiente para que os atores sociais em questão possam de fato construir um diálogo efetivo sem detrimento da segurança da informação.

70 Nesta perspectiva, sugere-se que a formalização da prescrição seja limitada, permitindo possíveis renegociações e ajustes das regras e das decisões, como forma de compatibilizar de um lado a prescrição com a natureza da atividade de atendimento e de outro a saúde dos operadores e a qualidade do atendimento.

\section{6. À guisa de conclusão}

71 Uma questão fundamental se coloca frente a estes cenários de produção. Quais seriam as conseqüências em termos do risco ligado ao empobrecimento da linguagem devido à disseminação deste tipo de modelo de sistema de produção em diferentes regiões do mundo? Conforme exposto neste texto, apontamos resultados que mostram as dificuldades encontradas para que os atendentes se comuniquem com os clientes e vice- 
versa. Trabalhar a partir de um cenário muito restritivo, no qual impera de maneira soberana o script, obriga as pessoas a restringirem a comunicação, o que muitas vezes, causa mal entendidos e, induz retrabalho, pois até que se resolva o problema do cliente, este entra em contato com a empresa várias vezes. $O$ atendente deve se restringir ao que ele pode falar e não deve se distanciar da maneira como a empresa definiu e padronizou. Este padrão serve, em princípio para ser o mesmo em qualquer sítio da empresa, que pode inclusive, se localizar em países diferentes.

Pensar esta situação ao contrário poderia trazer uma perspectiva completamente diferente, que, ao invés de favorecer um empobrecimento cultural resultante da prescrição da linguagem, poderíamos estar frente a uma perspectiva de enriquecimento cultural, possibilitado pelas trocas entre pessoas de diferentes origens. Em primeiro lugar, seria importante redefinir conceitualmente o que significa atender aos clientes. Ao invés de conceber o atendimento para propiciar um tipo de serviço massificado, despersonalizado, poder-se-ia projetar um serviço que desse suporte para que as relações de serviço pudessem incorporar a diversidade, tanto dos clientes como dos próprios atendentes. Reforçar os conhecimentos gerais, a capacidade de raciocínio, o domínio de diferentes linguagens por meio do aprofundamento de leituras e do conhecimento de diferentes aspectos que possam estar relacionados com a "cultura" do outro, seria um caminho inverso ao que é usualmente adotado pelas empresas. Ao invés de uma massa de atendentes que pouco sabe sobre os produtos, sobre os costumes daquela população, pensar em profissionais do atendimento que tenham condições de se desenvolverem por meio do enriquecimento cultural, da aquisição de mais conhecimento e, sobretudo que consigam acompanhar e resolver os problemas dos clientes.

73 A própria implantação das empresas, em várias regiões do mundo poderia ajudar a favorecer as trocas. Ao invés de se transferir modelos empobrecedores, que consideram as pessoas de uma maneira restritiva, poderiam ser desenvolvidos modelos de produção enriquecedores. Este tipo de modelo existe e se restringe principalmente a situações nas quais os clientes são considerados como preferenciais ou, em situações em que as empresas consideram a importância do conhecimento técnico sobre os produtos ou processos de serviços. Será então que o maior impedimento seria uma busca frenética para a redução de custos para as empresas e uma disseminação dos custos relativos às consequências para a saúde destas populações para os países mais periféricos na rede de produtiva ? Estaríamos então frente a um processo de exportação e disseminação das externalidades negativas para diferentes partes do planeta, uma vez que esses custos tem impacto na sociedade como um todo, e não apenas para os trabalhadores acometidos e para as empresas (Tertre, 2005).

Não seria o caso, então, de se considerar que há uma urgência e uma oportunidade ímpar para se mudar radicalmente os cenários de produção neste tipo de central de atendimento, enriquecendo de fato o conteúdo das tarefas e possibilitando que os profissionais possam se desenvolver, através de processos mais cooperativos, de maneira que aquilo que venham a fazer tenha, de fato, sentido (Sznelwar, Abrahão \& Mascia, 2007). Nesta mesma perspectiva, as mudanças organizacionais poderiam ter em perspectiva a emancipação dos sujeitos, uma vez que a melhoria destes sistemas de produção teria como base o reforço da cooperação, da construção da profissão e dos processos de realização profissional e pessoal dos sujeitos, em consonância com as propostas da psicodinâmica do trabalho (Dejours, 2009). 
Quando Wisner iniciou seus estudos em antropotecnologia tinha claro um pressuposto que guiou muito da sua trajetória como pesquisador, como professor e, sobretudo como pessoa. Ele afirmava que o trabalhador era sempre portador de uma inteligência, fossem eles considerados como operários não especializados independentemente da sua origem étnica ou mesmo do grau de desenvolvimento industrial de seu país. Para ele havia sempre inteligência e maneiras específicas de expressão cultural, fruto de uma história e de uma geografia. De certa forma, a disseminação de centrais de atendimento em todo o planeta, e, sobretudo, em alguns países considerados em vias de desenvolvimento industrial, ou melhor, como são chamados alguns países, os novos países industrializados, mostra que, de fato, há inteligência do outro lado. As operações são complicadas, exigem capacidade técnica, mesmo sendo o modelo adotado pelas empresas apoiado em paradigmas simplificadores. Esta afirmação mostra o paradoxo de se buscar enquadrar a realidade em um modelo restrito.

Apesar do empobrecimento resultante da rigidez dos scripts, os atendentes precisam dominar a situação, trabalhar com sistemas informatizados de difícil operação, conseguir criar estratégias que lhes permitam não sofrer em demasia ; afinal tudo isto requer pessoas competentes, capazes de dar conta destas situações. Então, podemos afirmar que de fato a inteligência envolvida em todas as ações de trabalho, inclusive nas discutidas neste texto, é fundamental para que se obtenha bons resultados, mesmo que seja por meio da astúcia, fundamental para que se dê conta do não prescrito. Por que não integrar esses pressupostos e assim constituir sistemas de produção em que, de fato, a inteligência dos trabalhadores seja reconhecida e esteja a serviço de um melhor atendimento e que permita desenvolver melhor os sistemas de produção e os próprios sujeitos que trabalham? Talvez porque, como disse Wisner em uma visita ao Brasil, "reconhecer a inteligência também significa remunerar melhor os trabalhadores".

\section{BIBLIOGRAFIA}

Abrahão, J. I. (1986). Les processus de maîtrise technologique : implantation de distillerie de canne à sucre rural brésilien (Tese de doutoramento não publicada). CNAM, Paris.

Abrahão, J. I. (2000). Resstruturação produtiva e variabilidade do trabalho ; uma abordagem da ergonomia. Psicologia : teoria e Pesquisa, 16(1), 49-54.

Abrahão, J. I., \& Torres, C. C. (2004). Entre a organização do trabalho e o sofrimento : o papel de mediação da atividade. Revista Produção, 14(3), 67-76.

CFDT. Confédération Française Démocratique du Travail. (2002). Centres d'appels. Enquête. Disponível em : http://www.cfdt.fr. Acesso em :setembro/2002

Dejours, C. (1987). A loucura do trabalho. Paris : FTA/Oboré.

Dejours, C. (1998). Souffrance en France. L'histoire immédiate. Paris : Éditions du Seuil.

Dejours, C. (2001). Le corps d'abord - Corps biologique, corps érotique et sens moral. Paris : Payot. 
Dejours, C. (2004). Ativismo profissional : Masoquismo, compulsividade ou alienação ? In Selma Lancman \& Laerte Sznelwar, (Orgs.), Christophe Dejours : da psicopatologia à psicodinâmica do trabalho (pp. 159-177). Brasília : Paralelo 15.

Dejours, C. (2008). Alienação e clínica do trabalho. In Selma Lancman \& Laerte Sznelwar (Orgs.), Christophe Dejours - da psicopatologia à psicodinâmica do trabalho (pp. 219-244). Rio de Janeiro : Editora Fiocruz.

Dejours, C. (2009). Travail vivant (Vol. II, pp. 176-183). Paris : Payot,

Gubert, K. B. (2001). Os determinantes da atividades em uma central de atendimento : o caso do disque-saúde (Tese de Mestrado não publicada). Universidade de Brasilia.

Guérin, F., Laville, A., Daniellou, F., Duraffourg, J., \& Kerguelen, A. (2001). Compreender o trabalho para transformá-lo (trad. Giliane Ingratta e Marcos Maffei). São Paulo : Editora Edgard Blücher.

Hubault, F. (2003). Le travail vaut par la manière dont on en use : contribution de l'ergonomie à la gestion des ressources humaines. In José Allouche (Coord.), Encyclopédie des ressources humaines (pp. 476-487). Paris : Vuibert.

Hubault, F., \& Bourgeois, F. (2001). La relation de service : une convocation nouvelle pour l'ergonomie ? In François Hubault, La relation de service, opportunités et questions nouvelles pour l'ergonomie (pp. 5-32). Paris : Octarès Editions.

Le Guillant, L. (1956, 2006). La névrose des téléphonistes. In Louis Le Guillant, Le drame humain du travail : essai de psychopathologie du travail (pp. 131-148). Ramonville Saint-Agnes : Éditions Erès.

Maggi, B. (2006). Do agir organizacional, um ponto de vista sobre o trabalho, o bem-estar, a aprendizagem. São Paulo : Edgard Blucher.

Mascia, F. L., \& Sznelwar, L. I. (1998). The organisation of work based on standardisation: the question of scripts in call centers. In Peter Vink, Ernst A. P. Koningsveld, \& Steven Dhondt (Orgs.), Human Factors in Organizational Design and Management (pp. 647-652). Amsterdam : Elsevier.

Negroni, P. (1986). Informatisation d'un bureau de poste : esquisse d'un transfert de technologie interne. Mémoire de DEA d'Ergonomie. Laboratoire d'Ergonomie du CNAM, Paris, France.

Salerno, M. S. (2001). Introdução. In Mario S. Salerno, Relação de Serviço : Produção e avaliação (pp. 10-22). São Paulo : Editora SENAC.

Sato, L. (2002) Saúde e controle no trabalho : feições de um antigo problema. In Maria das Graças Jacques \& Wanderley Codo (Orgs.), Saúde mental e trabalho : leituras (pp. 31-49). Petrópolis : Ed. Vozes.

Sennett, R. (2001). A corrosão do caráter. Rio de Janeiro : Editora Record.

Sznelwar, L. I., \& Mascia, F. L. (2000). Diálogo e constrangimentos do script na atividade de atendimento a clientes. In Laerte Sznelwar \& Leila N. Zidan (Orgs.). O trabalho humano com sistemas informatizados no setor de serviços (pp. 97-104). São Paulo : Plêiade.

Sznelwar, L. I., Abrahão, J. I., \& Mascia, F. L. (2007). Trabalhar em centrais de atendimento : a busca do sentido em tarefas esvaziadas. Revista Brasileira de Saúde Ocupacional, 31, 97-112.

Tertre, du C. (2005). Services immatériels et relationnels : intensité du travail et santé. @ctivités, 2(1). http://www.activites.org 
Torres, C. C. (2001). A atividade nas centrais de atendimento ; outra realidade, as mesmas queixas (Tese de Mestrado não publicada). Universidade de Brasília.

Wisner, A. (1994). A inteligência no trabalho. São Paulo : Fundacentro/Editora UNESP.

Wisner, A. (1997). Aspects psychologiques de l'anthropotechnologie. Le Tavail humain, 60(3), 229-254.

Zarifian, P. (2001) Mutação dos sistemas produtivos e competências profissionais : a produção industrial de serviço. In Mario Sergio Salerno (Org.), Relação de Serviço : produção e avaliação (pp. 67-93). São Paulo : Editora SENAC.

Zimmermann, R. M. (2005). o paradoxo entre sentimento de segurança e o controle em uma central de atendimento. (Tese de Mestrado não publicada). Universidade de Brasília.

\section{RESUMOS}

Neste artigo é proposta uma reflexão sobre o trabalho em centrais de atendimento à luz das propostas da antropotecnologia. As questões tratadas dizem respeito a pesquisas desenvolvidas em diferentes empresas, principalmente nos anos 1990 e 2000, situadas no Brasil onde a questão de problemas de saúde, como as LER / DORT e os distúrbios psíquicos, emergiram com níveis elevados de incidência e de prevalência. Os resultados das abordagens utilizadas, a da ergonomia da atividade e da psicodinâmica do trabalho, foram discutidos com relação à ampla disseminação deste tipo de trabalho em diferentes países, configurando uma modalidade de transferência e tecnologia. Assim a transferência de modos de organização do trabalho inspirados em pressupostos oriundos do taylorismo, desconsiderando a realidade vivida pelos trabalhadores e as singularidades de cada contexto são contestados.

Este artículo propone una reflexión sobre el trabajo en centrales de atención al cliente, a la luz de las propuestas de la antropotecnología. Los temas abordados se refieren a encuestas realizadas en diferentes empresas, especialmente en los años 1990 y 2000, que se encuentran en Brasil, donde la cuestión de los problemas de salud, tales como el RSI / trastornos musculoesqueléticos y los trastornos mentales, surgieron con alta incidencia y prevalencia. Los resultados de los métodos utilizados, de la ergonomía la actividad y de la psicodinámica del trabajo se discuten en relación a la amplia difusión de este tipo de trabajo en diferentes países, un modo de transferencia y tecnología. Así, la transferencia de modalidades de organizar el trabajo, inspiradas en el taylorismo, sin tener en cuenta la realidad vivida por los trabajadores y la singularidad de cada contexto é discutida.

Cet article propose une réflexion sur le travail dans les centres d'appels à la lumière des propositions anthropotechnologie. Les questions abordées concernent des enquêtes menées dans différentes entreprises, en particulier dans les années 1990 et 2000, située au Brésil, où la question de problèmes de santé, tels que RSI / TMS et des troubles mentaux, sont apparus avec une incidence et la prévalence élevées. Les résultats des approches utilisées, l'activité de l'ergonomie et de la psychodynamique du travail, ont été discutées en relation avec la diffusion à grande échelle de ce type de travail dans les différents pays, la fixation d'un mode de transfert et de la technologie. Ainsi, les modes de transfert de l'organisation des hypothèses de travail inspirées dérivées du taylorisme, sans tenir compte de la réalité vécue par les travailleurs et le caractère unique de chaque contexte sont contestés.

This paper proposes a reflection on work in call centers in light of proposals made in by an anthropotechnological approach. The issues addressed relate to surveys conducted in different 
companies, especially in the years 1990 and 2000, located in Brazil where health problems, such as RSI / WMSD and mental disorders, emerged with high incidence and prevalence. The results of the approaches used, ergonomics and work psychodynamics, were discussed in relation to the widespread dissemination of this type of work in different countries, setting a mode of transfer and technology. Thus the transfer modes of organizing work inspired assumptions derived from Taylorism, disregarding the reality experienced by workers and the uniqueness of each context are analysed.

\section{ÍNDICE}

Palavras-chave: antropotecnologia, centrais de atendimento, ergonomia, psicodinâmica do trabalho

Keywords: antropotechnology, call centers, ergonomics, psychodynamic of work

Mots-clés: anthropologie, centres d'appel, ergonomie, psychodynamique du travail

Palabras claves: antropotecnología, centrales de contacto, ergonomía, psicodinámica del trabajo

\section{AUTORES}

\section{LAERTE SZNELWAR}

Departamento de Engenharia de Produção, Escola Politécnica da Universidade de São Paulo, Av. Prof. Almeida Prado, trav. 2 no 128 Cidade Universitária, São Paulo, SP, BRASIL

laertesz@usp.br

\section{JÚLIA ABRAHÃO}

Departamento de Engenharia de Produção, Escola Politécnica da Universidade de São Paulo, Av. Prof. Almeida Prado, trav. 2 no 128 Cidade Universitária, São Paulo, SP, BRASIL

abrahao@unb.br 